\title{
LAPURUTH
}

Euskal ikerketen aldizkaria | Revue d'études basques |

Revista de estudios vascos | Basque studies review

$9 \mid 2004$

Numéro IX

\section{Etimologia eta neologia Larramendiren Hiztegi Hirukoitz-ean (1745)}

\section{Blanca Urgell}

\section{OpenEdition \\ Journals}

Édition électronique

URL : http://journals.openedition.org/lapurdum/882

DOI : 10.4000/lapurdum.882

ISSN : 1965-0655

\section{Éditeur}

IKER

\section{Édition imprimée}

Date de publication : 1 novembre 2004

Pagination : 299-310

ISBN : 2-68781-376-X

ISSN : $1273-3830$

Référence électronique

Blanca Urgell, « Etimologia eta neologia Larramendiren Hiztegi Hirukoitz-ean (1745) », Lapurdum

[Linean], 9 | 2004, Sarean emana----an 01 mars 2009, kontsultatu 20 avril 2019. URL : http:// journals.openedition.org/lapurdum/882 ; DOI : 10.4000/lapurdum.882 


\title{
Etimologia eta neologia Larramendiren Hiztegi Hirukoitz-ean (1745)
}

\author{
Blanca URGELL \\ EHU, Gasteiz
}

\section{Sarrera ${ }^{1}$}

"Euskara" eta "XVIII. mendea" elkarrekin ezin aipatu, "Larramendi" ere aipatu gabe. Halere, nola aipatu behar den, honetan ez gaude ados. Alde batetik, latina txikitan erraz eta laster ikasteko moduko josulagun buru handiko, predikari ospetsu, Espainiako erregina-amaren aitorle, eskolastiko trebe, euskaraz eta erdaraz idazle bikain, Hegoaldeko euskal literaturaren aita, gramatikalari egoki... dohain anitzez hornituta aurkeztu zaigu Larramendi ; diren eta izan diren euskaltzale eta euskalarietan argienetako bat.

Bestetik, ordea, edonon irakur dezakegu -oraindik ere bai, bost lekutan- hizkuntz ideia zaharkituak zituela, ez Garibaik edo Etxabek baino modernoago edo hobeak ; euskaldunentzat baino erdaldunei begira lan gehiago egin zuela, eta joera gaizto honengatik hanka-bururik gabeko etimologiez -edo txantxetakoez; ez dakit zer den okerrago- eta gaizki eratutako neologismoz bete zuela bere hiztegia.

Zilegi bekit berriro ez azaldu beharrik izatea Mitxelenak (1983) eta Lakarrak (1985, etab.), elkarren paretsuan eta beste egile batzuen laguntza berehalakoan erakarriz (Pagola 1984, Sarasola 1986, etab.), nola deuseztatu zuten ikuspegi hori hein handi batean, Mokoroak (1935) eratutako azalpena alderdi askotatik ahula ez zenean, zuzenean okerra zela erakutsiaz, garai garbizaleegi hartako -sabindarren garaiko- gehiegikeriek sortutako eta haiexek okertutako irizpidea, alegia.

Bazeuden gutxienez beste bi oker nagusi ikuspegi hartan. Lehena, Larramendiren ahotsa isilaraztea, haren esanak irakurri gabe eta haren eginak aztertu gabe epaitzea. Bigarrena, Larramendi gure munstroa bailitzan aurkeztea, euskararen egoera bereziak nahi baino maizago sortzen omen dituen aldrebeskeria edo gehiegikeria baztergarri bezain barkagarri horietako baten edo batzuen egilea.

Lan honetan erabiliko ditut bi gai horiek -Larramendik berak eskaintzen dizkigun datuak eta Europako hizkuntz ideien historiak XVIII. mendeaz dioskuna- irekitzen dituzten bideetako zenbait Hiztegi Hirukoitz-aren ezagutzan zenbait aurrerapausu egin nahirik, eta honetan jakintzat emango dut hiztegi erraldoi hura dela Hegoaldeko (eta ziurrenik ez bakarrik Hegoaldeko) euskarak XVIII. mendean duen gordailurik handiena, bai eta Imposible Vencido-aren aldean Larramendiren hizkuntz ideien islarik garrantzizkoena ere.

1 - Lan hau Joseba Lakarrak zuzentzen duen BFF202-03132 proiektuaren barnean egina da. 
XVIII. mendean oraindik ere giza hizkuntzaren etorkiari eta haren garapenari buruzko iritzi gehienak Bibliako tradizioan oinarritzen dira. Honek esan nahi du hizkuntza Jainkoaren dohaintzat hartzen zela, Babelen kokatzen zela hizkuntz aniztasunaren jatorria eta guk "hizkuntz aldaketa" deitzen diogun horri "ustelketa" zeritzela (Bahner 1966).

Aspaldixko hasi zen Historiografia Linguistikoa ohartzen zeinen garrantzizkoa den guretzat lehenagoko hizkuntzalarien jarrera itxuraz apalegi edo lañoegi haiek ulertzen ahalegintzea -"beren lekuan jartzea", esan ohi denez-, bestela nekez ulertuko dugulako zer egin zuten edota zer egin nahi izan zuten, eta nola (Koerner 1989, Hüllen 1990).

Lan honetan erakutsi nahi nuke, hain zuzen, tradiziozko ideia haiek -ordurako jadanik zaharkituta zeuden, ez zeuden, honek ez du axola hemen- erabilgarri suertatu zitzaizkiola Larramendiri euskara normaltzeko eratu zuen egitasmoan. Bidenabar, azpimarratu nahi nuke zeinen emankorra izan daitekeen aztertzea teoria orokorrek hizkuntza gutxituetan izaten dituzten ondorenak, baliabide eskasiak bestetan axaletik baino ukitzen ez diren gaiak sakonago -beste era batera, edonola ere- azterrarazten baitituzte eta zenbaitetan, gure gaurko autuan gertatu bezala, are ohiko mugak gaindiarazten. ${ }^{2}$

Larramendiren egitasmoan bi tradizio oso ezagun biltzen dira : hizkuntza beteginaren inguruan hausnarketa egiten duena (Eco 1994) eta etimologia kratilozalea (Genette 1976). Biak dira Hiztegi Hirukoitza-ren $(H H)$ neologiaren legamia.

\section{Larramendik euskarari buruz dituen ideiak}

Larramendi heziketa eskolastiko sendoko josulaguna izan genuen. Horrezaz gainera, bere liburutegiaren arabera (Altuna 1984) euskarari buruz edo Penintsulako hizkuntz historiari buruz eskuetaratzen zuen guztia irakurri zuen (Garibai, Poza, Etxabe, Oihenart, Moret..., baina baita Aldrete, Mayans, Pierre de Marca...). Ez dirudi, aldiz, gehiegi axola zitzaionik gramatikan edo lexikografian bere burua janztea. Hortik, agian, bere gramatikan sumatzen dugun teorizazio lan urria, edota eredu grekolatindarri atxikiegi lan egin izana (Oyharçabal 1989, Gómez 1992). Eta hortik $H H$-ak hiztegigintzaren tekniken aldetik daukan itxura arkaiko xamarra, bai eta eredu bakar baten -Espainiako Erret Akademiaren Diccionario de Autoridades-en- ia erabateko menpekotasuna (Urgell 1999).

Orobat, ez dira berriak, hasiera batean bederen, hizkuntzari buruz eta giza hizkuntzari buruz oro har Larramendik dituen ideiak, zeren eta bere egiten baitu apologi tradizio luze-luze bat, eta horko ekarriak bere erara landuaz tradizio horren erpin bihurtzen da (Mitxelena 1959). Denok ezagutzen duguna labur bilduz, Larramendik sinesten $\mathrm{du}$, aurreko guztiek bezala, euskara ama-hizkuntzetako bat dela, Babelgo nahasketaren ondoren sortutako 72 hizkuntzetatik bat, aurkintza hauetara Tubal Noeren ilobak ekarria ; Penintsulan mintzatu zen lehen hizkuntza dela, eta aspaldi hartan mintzatzen zen bakarra, hots, Penintsula osoko antzinako hizkuntza. Eta, ama-hizkuntza izanik edo, zehatzago, Jainkoak zuzenean sortua izanik, hizkuntza betegina izan behar -“arrazoiaren hizkuntza” deritzo Larramendik, Descartes buruan, nonbait, bere lehen idazkietan -, zeren eta euskarak baititu

2 - Ideia hau jadanik Swiggers 1990-n aurkitzen da ; zehazki, berak hizkuntz ukipeneko eremuak aipatzen ditu, XVIII. mendeko hizkuntz ideien mintegi gisa. 
...aquellas perfecciones que en una o varias lenguas han sido admitidas de todos por perfecciones y atributos apreciables, v.g. la propriedad de las voces, la distinción y puntualidad en los modos de hablar, la cortesía y discreción, el concierto y seguridad de las reglas, la consequencia dellas, la harmonía en su dispositiva, y la riqueza y abundancia (1728: 92).

Dena den, Larramendik bai hiztegigintzan, bai hizkuntz ideien alorrean, bietan egin zituen ekarpen berri eta jakingarriak, hizkuntza baten lexikoaren aberastasun eta egokitasunari buruzko teoria bereziak garatu baitzituen, eta teoria horiek hitzberrigintzan eredu gisa erabili.

\section{Hizkuntz normalkuntzarako oinarri teorikoak ${ }^{3}$}

Mayans-ek (1737 : 347-348) euskara aurkeztu zuen erabilera faltak eta landu ez izanak usteldutako hizkuntza gisa. ${ }^{4}$ Larramendik nahiago du azpimarratu hizkuntza bizi eta hilen arteko aldea, eta gogoratzen du hebreerak, grekoak eta latinak, nahi bezain perfektuak izanik ere, betiko galdu dutela berriztatzeko gaitasuna (1745 : xxxiii). Ez, ordea, euskarak, lortu baitu bizirik irautea, Penintsulak jaso dituen inbaditzaile guztiak gorabehera :

...antes universal y estendidíssima por toda España, después más ceñida, y últimamente reducida al Sagrado destos montes, en que logra una vida y salud robusta, nada expuesta a la caducidad de las demás Lenguas. (...) encastillada entre estas rocas, a pesar del tiempo y sus estragos, ha sabido mantener su alma y cuerpo vivientes en un estado tan vigoroso y fuerte, que va a remozarse y aspira a la immortalidad (1745: xxxiii).

Ez da ustelketarik izan, beraz ; besterik gabe (eta zuhurki) atzera egin du euskarak, eta "mendi hauen babesean" jarri. Adierazpen honek ez du esan nahi Larramendik ukatzen zuenik maileguek euskaraz duten garrantzia. Alderantziz, zentzuzko bereizketa bat ezarri zuen erdarakada (hitzunea, Ubillosek HH-tik atera zuen terminologian) eta etxekotutako maileguen artean (1745 : xlvii-xlviii), eta zehaztu zuen etxekotuak euskararen arauen araberako bihurtu direla, hizkuntza aberastuz aldatu gabe (1745 : eskaintza, or. gabe). Latinari dagokionez, uste zuen maileguak bi norabideetan joan direla eta, zehazkiago, eguneroko hizkuntzaren hitzak eta gauza arrunten izenak, horiek denak euskarak eman dizkiola latinari (1745 : xvii-xix). Baina, gainerakoan, hizkuntzaren bizitzaz diharduenean gai hau saihestu ohi du. Onartu, onartzen du denboraren iragateak eta hiztunen axolakabekeriak hitz asko galarazi dituztela (1745: x-xi).

Hegoaldeko euskaldunek gaztelaniarekiko daukaten kultur menpekotasuna aitorturik (1745 : xliii), Larramendik erabakitzen du euskarak egin behar duela latinak grekoarekin edo gaztelaniak latinarekin egin zuten bezala, hau da, haren

3 - Hurrengo guztian, salbuespenak salbuespen, Larramendiren adierazpenen erreferentziak ematera mugatuko naiz, oso-oso argiak izaten dira eta ; ikusi ahalko denez, gai bera eta ia-ia argudiaketa bera $\mathrm{HH}$ aren hitzaurreko atal bat baino gehiagotan agertzen dira, testuinguru ezberdinetan eta, are garrantzizkoago, zati apologetiko eta lexikografikoetan errepikatuta : bi arloak elkarrekin oso lotuta zeudelako beste froga bat, zalantzarik gabe. Halaber, gehienetan ez ditut aipatuko garaiko beste egile batzuekin (guztiz espainiarrekin) dituen iritzi kidetasun eta batetortzeak, gure helburuetatik at geratzen den azterketa xeheago bat merezi dute eta.

4 - Mayansek uste hori bermatzeko erabiltzen duen testua (Landuchio 1562) ez da erabil zezakeen erakusgarririk onena, jakina, jadanik Tovarrek argitu zuen bezala (1980:80-81). Tovarrek, horrekin batera, Mayansen argitasun handiagoa ere azpimarratzen du, Larramendik baino hobeto ulertzen baitu Penintsulako hizkuntzen bilakabide historikoa. Halere, gogoratu behar da (Lakarra 1985-ekin bat etorririk) Tovarrek euskarari buruzko hausnarketen historia progresibista bat aurkezten duela, eta ikuspegi honen barruan ez dagoela ulertzerik Larramendiren ezinegona, euskara normaltzeko asmoa izanik, ikusten duenean zeinen lekukotasun eskasa -erdarak bortizki kutsatutako hizkera batekoaerabiltzen duen Mayansek. 
parean jarri behar dela. Ia hogei urteko lana izango zenerako lehen hurbilketa tolesgabe xamar honetan, gaztelaniazko hiztegirik osoena hautatzen du eta bertako sarrera guzti-guztietarako euskal ordainak aurkitzen jarri nahi du. Alabaina, berehala ohartzen da lana erraldoia dela, eta are "eramangaitza", ez hiztegigintza tradiziorik, ez ia libururik ez duen eta eskolan erabiltzen ere ez den hizkuntza batean. "Para salir con ese intento, lo segundo a que me dediqué fue a aprender el bascuence..." (1745: lii). Ideia honetan bat dator, esate baterako, Schottelius alemanarekin (Seiffert 1990), eta ideia horren lehen fruitua bere gramatika izango da, non berariaz uzten duen hiztegirako "izenen eraketa" deritzana eta antzerako gaiak (1729: 268).

Feijoo-ren aburuz (1726: 216-221), hizkuntzaren aberastasuna frogatzeko aintzat hartzekoak izan ohi diren hiru ezaugarrietan -oparotasuna (copia), egokitasuna (propriedad) eta harmonia-, copia bakarrik (hitz ugari izatea) dugu neurbide ziur eta esanguratsu. Feijooren murriztapen hau oso gogorra da euskara bezala gutxi landu izan diren hizkuntzetarako ; honegatik Larramendik, euskara txiroa dela aitorturik (1745 : ix), nahiago du aberastasun mota bi bereizi : ${ }^{5}$

...qué riqueza y copia es la más apreciable en una Lengua ? Es en dos maneras la riqueza de las Lenguas, y quiero explicarme con términos de Escuela : una es la riqueza formal, y per se ; otra es material, y per accidens. La riqueza formal consiste en la variedad de preceptos, en la seguridad de las reglas, en la hermosura y harmonía de la Syntaxis, y en otros atributos que son efectos de la idea, de la inventiva, de la comprehensión del Inventor de las Lenguas. (...)

La riqueza material y per accidens de una Lengua, consiste en la multitud de vocablos sueltos, sean synónimos o no lo sean (1728:117-119; 1745 : ix-x).

Bai euskararen aberastasunaz hitz egitean, baita hiztegia nola egin zuen azaltzerakoan (1745 : ix y xlv-li), bietan Larramendik hitz arruntak eta hitz "fakultatiboak" -Zientzia, Arte eta Fakultateetakoak- bereizten ditu. Hitz arruntak direla eta, uste du gaurko euskararen formazko aberastasunak (hots, baliabideetan aberatsa izateak) erakusten duen bezain aberatsa izan zela gure hizkuntza jatorriz baita materian ere (1745: x), baina jatorrizko copia hura egun euskalkietan sakabanatuta dagoela (1745: xii, xlv eta lii).

Hitz fakultatiboei dagokienez, euskarak, beste edozein hizkuntzak bezalaxe, eguneratu beharra dauka, eta honetarako aukeran maileguak onar ditzake, zein berezko ordainak sortu $(1728: 123 ; 1745$ : xl eta xxxiii). Larramendik bigarrena hobesten $\mathrm{du}$, Ciceronen bidetik (1745 : xi). Gogora dezagun, bidenabar, garai horretan ari zirela deskubritzen hizkuntza askoren mekanismo morfologikoak (cf. Schottelius ; Jones 1991), eta horrek sortzen duen mirespenaren ildotik berez sortu zela "sortzaile" dei dezakegun lexikografia bat, hiztegigilearen hizkuntz gaitasuna gehiago islatzen baitu, hizkuntzaren benetako egoera -iraganekoa edo egunekoabaino (Lakarra 1995). Hitz berriak behar izatea eta hizkuntzaren ahalmen sortzaileaz ohartzea, bi alderdiek dute eraginik Larramendiren egitasmoan.

Alabaina, ordainak ezin dira nolanahi sortu, hizkuntzaren legeen arabera baizik : Larramendi biziki kezkatzen duen gaia dugu hau (1745 : x, adib.). Honegatik, gorde nahi luke egingo dituen hitz berrietan ondare zaharreko hitzetan aurkitzen duen egokitasun berezi hori, hots, motibatuak izatea nahi du, ez arbitrarioak ; hau dela

5 - Logika tradizionalarena da materia eta formaren arteko bereizkuntza perpausean. Jadanik seinalatu da (Lázaro Carreter 1985 [1949], Breva Claramonte 1985, Lakarra 1993) bereizkuntza hori lexikoari aplikatzea berrikuntza bat dela. Iruzkingile batzuek diotena diotela, ohar bedi Larramendik urte batzuk kentzen dizkiola Armestori, nahiz horiek 1745eko bertsioa bakarrik ezagutu. 
eta, oso esanguratsua da bi aldiz aipatzea Platonen Cratilo-a, lehenik euskararen perfekzioak aipatzerakoan (1745 : ii) eta bigarrenik hiztegiko hitzak nolakoak izango diren azaltzerakoan ; bigarren honetan, gainera, aipua euskarara itzultzen du, "denek uler dezaten" (1745: 1).

Labur bilduz, Larramendik hiru aldiko lana egin zuen : bilketa, analisia eta hitz sorkuntza. Edo, bere hitzetan esanda, lehenik bilatzen ditu

...voces simples oportunas que explican sus objetos simplemente, o compuestas que declaran su naturaleza y propriedades, y passo luego a formar los nombres facultativos que explican naturalmente sus objetos, en el sentido del mismo Platón (loc. cit.).

Larramendiren sistema ulertzeko gakoa honetan datza, alegia, "euskal hitza" bere ustetan zer zen mugatzean, hiztegian sartzeko modukotzat zer hartzen zuen erabakitzerakoan. Apologiatik bi ideia berreskuratu behar ditugu hori jakiteko : euskarak bere hartan iraun duela Babeldik hona, eta euskal hitzen ezaugarririk aipagarriena adierazten duten horrekiko berezko lotura -lotura naturala- gordetzea dela. Lehenengo ideiaren kariaz, erabakitzen du euskalki eta garai guztietako hitzak bildu behar dituela ; bigarrenetik, neologismoak egiteko bidea lortzen du. Hortaz, euskal hitzak izango dira antzina izan zirenak, gaur egun direnak (zein-nahi euskalkitakoak) eta hizkuntzaren legeen arabera sortutakoak. Halere, zehazten du azken hauei ere ezin zaiela adiera hertsian "berri" deitu :

Son nuevas, pero no ad placitum, ni a mi solo placer y regalado gusto, sino naturalíssimas al significado de las voces simples de que se componen, cuya análisis está descubriendo su oportunidad. Son nuevas, no para el Bascuence, sino para el Bascongado, que no ha querido, o no ha podido descubrir, ni registrar los tesoros que encierra su fecundíssma Lengua (1745 : xlix).

\section{Hitzberrigintza}

Oinarri teoriko horien gainean eraiki zuen Larramendik bere hiztegia, gutxi gorabehera 43.000 gaztelaniazko sarrera dituen lan erraldoi bat, 87.000 bat euskal testu-hitz biltzen dituena, agian 40.000 bat lema ezberdin (Sarasola 1997, Urgell 2000).

$\mathrm{HH}$-aren lexikoaren \%80 inguru lehen lekukotasunak dira. ${ }^{6}$ Artean hitz herrikoien lehen lekukotasunak ere egon arren (\%14, gutxienez) ${ }^{7}$ aipagarria da eta nabaria lehen lekukotasun gehienak eratorriak $(\% 50)^{8}$ edota elkartuak $(\% 22)^{9}$ direla, eta bi multzoetan taiu bereko hitz asko eta asko daudela. Zenbaki horiek aski eta sobera dira, inondik ere, Zgusta-k (1989) "standard-creating dictionary" deritzanaren kasu bereziki argi baten aurrean gaudela erabakitzeko. ${ }^{10}$

Aurreko atalean iruzkindu ditugun teoriek hala iragartzen zuten. Teoria eta praktika elkarrekin doaz Larramendiren egitasmoan, ondokoan erakusten saiatuko naizen bezala.

6 - Erabiltzen dudan laginean (H)A hasierako euskal hitz guztiak sartuta daude : 4.867 lema, orotara. Zehaztasun gehiegirik gabe zenbatuz, eta gehienbat aldaerekin eskuzabal jokatuz, ateratzen zait 1745 baino lehen lekukotutako hitzak 1.037 direla. Xehetasun gehiagotarako, ikus Urgell 2000.

7 - Orotara 532 hitz, adiera edo esapide bermatu ahal izan ditut, geroko lekukotasun ahozkoei esker eskuarki, baina lana ez dago amaituta, argitaratzen den ia hiztegi dialektal bakoitzak berrespenen bat ematen du eta. Kontuan har bedi, gainera, pentsatzekoa dela $\mathrm{HH}$-an ahozkotik hartutako hapax bat baino gehiago egongo dela. 8 - 2.435 eratorri gure laginean; horietatik 2.199 (\%90) lehen lekukotasunak.

9 - Laginean 1.070 hitz elkartu daude, eta horietatik 968 (\%90) lehen lekukotasunak dira.

10 - Eta egile horrek egozten dien data (gutxi gorabehera I. Mundu Gerratik aurrera) baino askozaz lehenagokoa. Kontuan har bedi Zgusta batez ere Afrikako eta antzeko hizkuntzen garapenaz ari dela. 


\subsection{Galdeketa eta hustuketa}

Antzinako copia euskalkietan sakabanatuta baldin badago, euskal lexikoa osatu nahi duenak ezinbestean hiztunen ezpainetatik eta dauden liburuetatik bildu beharra dauka. Frogatuta dago Larramendik galdeketa zabalak egin zituela : hartarako erabili zuen metodoaren deskribapen xehe-xehe eta oso interesgarri bat egin zuen (1745 : lii-liii). ${ }^{11}$ Frogatuta dago, halaber, hiztegirako bildu eta hustu zituela aurreko liburu ia guztiak, bai eta eskura izan zituen hiztegiak ere. 1. adibidean hiztegiko sarrera bitako euskal hitzen jatorria -euskalkia edo testuajasotzen dut, esate baterako :

(1) Clavo, iltzea [G], ultzea [B], itzea [L]

Espuma, a parra [G], bitsa [B], pitsa [G], abuina [Ax], haguna [Leiz]

Bidenabar, azpimarratzekoa da bere ustetan euskarak dituen hiru euskalki nagusietako ordainak ahalik sarrera gehienetan emateko ahalegina ; horrekin bateratsu, errepara diezaiogun G-B-L ordena finko xamarrari, sarreretan euskal ordainak antolatzeko Larramendik baliatzen dituen irizpideetako bat baita, bai $\mathrm{HH}$ an (2a), baita Eranskin-ean ere (2b) :

(2) a. (En ningún) lugar, iñon ere, iñon bere, nihon ere

(Es a) saber, conviene a saber, esan nai det, gura dot, erran nai du

Mariposa, inguma [G], chiqueta [G?], chirita [G?), micheletea [B], u lifa rfalla [Ax]

b. Costumbre, ecandua [RS], aztura [Ax]

Cebo, peita [G?], beita [Ax]

\subsection{Antzinako euskararen aztarnak}

Euskara beti bat izan baldin bada, egun ahaztuta dauden hitzek han-hemen utzitako aztarnak ere bildu beharko dira, bilketa honetatik lortutako emaitzak euskal hiztegian eskubide osoz (ez arkaismo gisa) jaso ahal izateko. Honetan Larramendik hiru iturritara jotzen du : (1) Toponimia-Antroponimietara, (2) beste hizkuntzek mailegu gisa gorde dituzten euskal hitzetara eta (3) euskal hitzen euren azterketara.

\subsubsection{Toponimia eta Antroponimia}

Aspalditik Toponimia zen euskara Penintsulan lehena eta orokorra izan zela frogatzeko erabiltzen ziren argudioetan landuenetako bat; berez bezala dator, hortaz, Larramendik bertan bilatzea antzinako hizkuntzaren aztarnak. Toponimo eta antroponimoak biltzen eta aztertzen ditu, beraz, eta lan horren ondorioz (3a) $\mathrm{HH}$ an berrerabiltzen ditu, edota ( $3 \mathrm{~b}$ ) adiera hertsian "neologismo" deitu behar ditugun hitzen oinarri bilakatzen :

(3a) Arruti deitura (1566, ap. ApV90) > arro + -ti > arruti "arrogante".

Arrokia deitura (1340, ap. ApV 92) > arro "esponjoso" + -ki > arroki "esponja".

11 - Ohar bedi, bide batez, Feijoo baino zertxobait lehenagoko garai batez ari garela, Feijoo hartzen baita Espainian dialektologi galdeketen aitatzat. 
(3b) a rrutiro "arrogantemente", a rrutitu "jactarse".

arrokarri "piedra pómez" (2. osagaia arri "piedra" delarik), arrokitu "esponjar".

Toponimiaren garrantziaz jabetzeko hona hemen A letran bildu ditudan Gipuzkoako herrien izenak (toponimia txikia ere ageri da, ordea), beren azalpen batzuetan oso xelebreekin :

(3c) ABALZIZKETA “Melodrama, diálogo en música, a balcizqueta , otseztizqueta". ADUNA "Trigo nuevo, aduna".

AMEZKETA “Carvallar, a mezqueta, a mezaga”. "Quexigal, a mezqueta, ameztia".

ARRASATE "Demolición, arrasatea, barraiadura, deseigoa, deseguindea, lurreratzea".

ASTIGARRAGA “Arboleda de ellos [tilos], a stiga rraga, a stiga rdia".

Baita Bizkaiko herri zenbait ere, batere nekerik gabe bilduak:

(3d) GETXO : "Humillo, quecho, guechoa".

LARRABEZUA: "Pasturage, la rre gucia quicoa, la rrabezua".

MAÑARIA: "Mañero, el que tiene maña, mañeru, ma ñaria".

MARKINA : "Margen, esta voz y la Latina margo, marginis, son de el Bascuence marguina, marquina, que significa lo mismo (...). Marguina, ertza, bazterra". Cf. "Margenar, marginar, marguindu, marquindu, ertzatu, baztertu". "Marginal, marguinarra, ma rquindarra, ertzecoa, bazterrecoa".

OROZKO : "Público, otsandequia, ochandiquia, a guerria, aguiria, ja quiña, orozcoa". "(Muger) pública, emacume orozcoa".

Baina toponimoak zatitu ere zatitu daitezke, erroez, atzizkiez eta elkarbideez informazioa eman dezaten. Adibide egoki bat izan daiteke -di atzizkiaz eratorritako hitzen $H H$-ko ugaritasun nabarmena, nahiz atzizki hori euskara historikoan ia antzua izan, baina Toponimian eta Antroponimian maiz aurkitzen zuena $:^{12}$

(4) aga di "palazón" (aga "palo"-tik sortua), andredi "mugeriego, conjunto de mujeres" (andre "mujer"-tik), arraundi "palamenta, conjunto de remos" (arraun "remo"-tik), etab.

\subsubsection{Beste hizkuntzetako euskal maileguak}

Bestela epaitu badira ere, Larramendiren etimologiak ez dira euskararen aldeko tour de force gutxi-asko zoro bat; ez bakarrik behintzat, ez eta gutxiagorik ere. Eremu honetan ere lanean dabil antzinako formen bila : bere ustetan, euskararekin harremanetan izan diren hizkuntzek gorde dituzte antzinako forma galdu horietatik batzuk, guztiz gaztelaniak, baina baita latinak, grekoak, etab. Hortaz, etimologiek ere elikatzen dute hiztegia, (5a) etxekotutako mailegu zenbaitez "jabetzeko", (5b) berriak gehitzeko eta (5c) haietatik ateratako erro-atzizkiekin neologismoak egiteko bidea emanez :

12 - Ezaguna da, ordea, ez zela bera izan horretan aritutako bakarra, ez lehena : Ziburuko Etxeberrik eta Harrietek ere gutxienez baliatu zuten toponimiatik kanpora. 
(5a) abere "a nimal" [1562] : "Aberes, hazienda, riquezas, viene de el bascuence abere, ganado, y antiguamente las riquezas eran en ganados, y por esso a los ricos llamamos aberatsac, como el latín pecuniosos de pecus".

adobatu "remendar" [1562] : "Adobar, es voz puramente bascongada, de adoba, adobatu, remendar, y este verbo de oba, obatu, obe, obetu, mejorar, y es lo que se procura remendando".

(5b) a bolla tu "abollar": "Viene de el Bascuence bollá, que significa el batán que tunde y golpea los paños; o de boillá, redondo".

agasajo "agasajo", agasajatu "agasajar" : "Agasajar, de agasajo, y esta voz de el antiguo castellano gasajo, cuyo origen puede ser de el bascuence guizagajo, hombre digno de lástima ; y esta expresión, con que recibimos a los que llegan maltratados de el camino...".

(5c) a bolla ntza "abolladura", a bolla ri eta a bolla tza lle "abollador", a bolla tze "abolladura". a ga sa ja tza lle "agasajador", a ga sa ja tze "agasajo".

Etimoak ere -baita euskaratik datozen gaztelaniazko hitzak eurak ereberranalizatuak dira. Adibidez, (6a) euskaraz ere emankor den gaztelaniazko -dura atzizkiaz jabetzen da; eta (6b) elkartu-eratorrien lehen osagaiaren bukaerako $o>a$ aldaketaz ohartzen da, nahiz ordurako fosildurik egon, eta berrezartzen du neologismoetan (ez beti testuinguru egokietan, eta honek salatzen du bestek baino argiago, jakina) :

(6a) "Alzadura, es voz puramente bascongada, altzadura". "Asmadura, es voz enteramente bascongada, y viene de a smatu, asmar".

a lga indura "costura", arrascadura "rascadura", arregura "regadío, regadura", a tzekidura "raboseada, raboseadura".

(6b) "Zulaque, betún para embetunar los caños, arcaduces, es voz bascongada zula quea (...) de zuloa, agujero, y guea, posposición que significa sin o negación, que en composición es también quea".

a rda beltx "tintillo" (a rdo "vino" + beltz "negro"), baina a rdo < *arda no, ardanelkartu-eratorrietan : cf. a rda ndegi "taberna" (1643) o a rda ntza "viña" (1164).

\subsubsection{Euskal hitzen azterketa}

Bildu ahal izan zituen hitz anitz ere -zaharrak zein berriak, orokorrak zein euskalkietakoak- analizatu zituen Larramendik. Zoritxarrez, gehientsuenetan ez ditu bere ondorioak agerian jartzen, eta honegatik zatika baino ez ditugu ezagutzen oraingoz ; halere, badirudi Larramendik egindako lan horrek ez duela parerik (emaitzen kopuruan, behinik behin) aurreko euskal gramatikagile edo hiztegigileek egin zuten lanetan. Ikus ditzagun alderdirik nabarienetako batzuk :

1) Atzizki asko isolatzea lortu zuen. ${ }^{13}$ Ondorioz, $H H$-ko eratorpen neologikoa oso ñabarra da, askotarikoa, baliokidetzat (zuzen edo oker) hartzen dituen atzizkiak aldizkatzen baititu maiz, hizkera batekoak edo bestekoak diren begiratu gabe :

(7) Assegurador, segurutzallea, seguruguillea (seguru(tu) + -tzaile, + gile). Mañoso, mañatsua, mañaduna, mañatia (maña + -tsu, + -dun, + -ti).

13 - Gure laginean Larramendik 72 atzizki ezberdin ditu, eta Urtek 52, esate baterako (Urgell 2000). Esan gabe doa denak ez direla emankorrak; halere, zenbakiok $H H$-ko aberastasunaren erakusgarri onak dira. 
2) Elkartu-eratorrien morfema-mugan gertatzen diren (edo gertatzen ziren) hots-aldaketa mordoxka batez jabetu zen. Gai honetan, batzuetan asmatu egin zuen, asmatu ere, baina interpretazio txarrak ere ez dira gutxi : ikus a rdabeltxa (6b)$\mathrm{n}$, esaterako. Interpretazio txar horiexek dira, antza denez, Larramendiren hitz berri askori itxura xelebre hori eman dietenak. Halaber, lotu beharko genituzke atzizki batzuen alomorfo ezezagunak ugari agertzearekin ere :

(8) -gintza atzizkiaren-intza alomorfo ezezaguna : argintza "cantería" (s. XVII ; a rgin "cantero" + -gintza) vs. a stela rintza "semanería" (a stela ri "semanero" + -intza).

-era atzizkiaren -dera eta -tera alomorfo ezezagunak : a ka bera "conclusión" (1713 ; a kaba(tu) "acabar" + -era) vs. alargundera "viudedad" (alargun "viudo" + dera), a urtera "niñez" (a ur "niño" + -tera).

bai eta testuinguru eta alomorfoaren artean egoten den erlazioaren galerarekin beste batzuetan :

(9) -gin atzizkiaren -kin alomorfoa herskari edo txistukariaren ondoan agertzen da : altzairugin "(fabricador de) acero" (altzairu "acero"), a meskin "soñador" (a mets "sueño") vs. a izekin "abanico" (a ize "aire"), a sgin "festejo" (a ts "respiración").

\subsection{Neologismo kratilozaleak}

Behin datuak bildu eta analizatu ondoren, neologismoak egiterakoan agertzen zaigu kratilismoa ez teoria gisa, arau praktiko gisa baizik. ${ }^{14}$

Euskararen ezaugarrietako bat hitzak motibatuak izatea baldin bada, eta hitzak aztertuaz deskubritu baldin baditugu arautzen dituzten mekanismoak, orduan egingo ditugun hitz berriak ez dira nolanahikoak izango : hizkuntzaren legeak eraketaren aldetik ez ezik, filosofikoki ere errespetatuko dituztenak izango dira. Alde honetatik, oso argigarri suertatzen da XVII. mendeko Covarrubias gaztelaniazko hiztegigilearen definizioa, atzekoz aurrera jartzea aski baita neologismo kratilozale bat nola eratzen den ulertzeko : "En la etimología de cada vocablo está encerrado el ser de la cosa, sus cualidades, su uso, su materia, su forma, y de algunas dellas toma nombre" (s.v. etymología, ap. Seco 1987 : 114 ; etzana nirea).

Eratorpena berez dugu kratilozalea ; elkarbidean aurkituko ditugu, beraz, adibiderik borobilenak. Larramendik hitz berriaren osagaiak aukeratzeko -Covarrubias-en harako algunas dellas hori- erabiltzen duen iturria maiz da (10a) $H H$-an jasotzen duen gaztelaniazko definizio edo bereizgarri laburra, edota (10b) $D A u$ t-eko definizioa, edo (10c) bertako etimologia ; bide batez, honek erakusten digu Akademiaren hiztegia eredu lexikografikoaz gehixeago ere izan zela Larramendirentzat :

(10a) abrebasle "quatrero, ladrón de bestias" (abre "bestia" + ebasle "ladrón") aderna "pitón, cuerno que empieza a salir" (adar "cuerno" + erne "brotar").

(10b) arra utsi bedar "salsafrás, salsifrás, yerva" < DAut "...se les dió este nombre (...) por la virtud que tienen de deshacer y quebrantar la piedra que suele formarse en los riñones" (arri "piedra" + autsi "romper" + bedar "hierba").

14 - Halere, azpimarratu behar dugu Larramendiren etimologiak ere askotan hertsiki kratilozaleak direla ; cf., adibidez: "Arda, animalejo conocido, vivíssimo, ligeríssimo : viene de el Bascuence, o de ari da, sincopado en $a r d a$, y significa, siempre se mueve y anda ; o de arin da, que significa que es muy ligero" edo "Alcalde, puede venir con toda propriedad de el Bascuence alcatea, que significa poder de cadena, de al, alá, poder, y catea, cadena". 
a untzorein "tragelafo" < DAut, s.v. tragelapho : "Animal que es de naturaleza media entre ciervo y cabra, porque resulta por generación de los dos" (auntz "cabra" + orein "ciervo").

(10c) a rla tx "vinagre" < DAut "Es compuesto de las dos voces, Vino y Agrio" (a rdo "vino" + latz "agrio").

atzbelar "escabiosa, yerba" < DAut "El zumo que se saca de ella es mui saludable contra la sarna y roña, de donde parece tomó el nombre del Latino Scabies, que significa la Sarna" (a tz "sarna" + belar "hierba").

Halaber, (11a) gaztelaniazko hitzaren kalko zuzena egitera ere jotzen du batzuetan, edo (11b) latinezkoaren, edo (11c) are grekozkoaren kalkora, noiz eta hizkuntza hauetan dagoenekoz erreferente kratilozale bat aurkitzen duen, hau da, elkartu bat edo sintagma baliokide bat :

(11a) a kirin "cabrón castrado" (a ker "cabrón"+ irin (du) "castrado").

a rgi iges "lucífugo" (a rgi "luz" + iges "huyendo").

arraianre "pexemuller" (arrai "pez" + anre "mujer").

arriolio "petróleo" (arri "piedra" + olio "aceite").

(11b) abarte "claro en la Arquitectura" < lat. intercolumnium (abe "columna" + arte "entre").

a rakaro "encarnadura" < lat. carnis temperies (a ragi "carne" + a ro "sazón").

a rbazkatu "encarnizarse" < lat. carnes vorare (aragi "carne" + bazkatu = vorare).

(11c) aldizenda "metonymia" < DAut "Es voz Griega, que vale Mudanza de nombre" ( alda (tu) "mudar" + izen "nombre" + -da atzizki izengilea, -te-ren aldaera HH-an) ; a storro "onocrótalo, ave" < DAut "Su grito o graznido es semejante al rebuzno del asno, y por esso le llamaron Onocrótalo en Griego, de ones, asno, y crotalos, grito o ruido" (a sto "asno" + orro "grito").

\section{Azken hitzak}

Larramendi bat dator garai hartako beste egile batzuekin bere hizkuntza denboraz kanpokotzat -hiztunek egiten duten erabilera xumetik atetiko edo goragokotzathartzean, betiereko arauak dituen berezko esentzia edo (Orixek esango lukeenezedo) goi-isurizko zerizantzat ; eta, beste askok bezala, ondorioztatzen du hizkuntzaren azterketak ezinbestean argitu beharko dituela funtsezko arau horiek. Bat dator, halaber, intuizio horren ahalmen sortzaileaz ohartzen direnekin eta, euskara kultur hizkuntza bihurtzea izanik hausnarketa hauen guztien xedea, burubelarri sartzen da euskararen deskribapen gramatikala egiteko eta haren sorbideak argitzeko lan nekagarri eta arazotsuan : ezina omen zen lan horretan.

Nabari diren baina ziurrenik espero behar genituen batetortze hauezaz gainera, Larramendiren egitasmoak badu gutxienez osagarri bat besteetatik zeharo ezberdin bilakarazten duena, dakidalarik : bere hizkuntza diglosi egoera larri batean dagoela argi izatea, alfabetatua egotea eta gaztelaniaz jakitea, biak bat izatea.

Ikuspegi honetatik ez dago neologismoak sortzera mugatzerik, nahiz hori ere oso beharrezkoa dela jakin ; Larramendik neologia argudiaketa sendo batez lagundu beharra ikusi zuen, euskaldunak gonbidatu behar baitzituen, lehenik, beren 
hizkuntzan alfabetatzera (gramatikaren bitartez) eta, bigarrenik, hizkuntza erabiltzera arlo guztietan (hiztegiaren laguntzarekin).

Argudiaketa horren alderdirik esanguratsuenetako bat da hemen aurkeztu dudana : tradiziozko etimologia, analisi morfofonologikoaren hasikin zenbait eta hitz eraketa, hirurak biltzen dituena, oraintsu arte euskararen apologia hustzat hartu ohi ziren arren, beren arteko lotura teorikoa ikusi gabez.

\section{Bibliografia}

- Altuna, Patxi, 1984, "La auténtica biblioteca de Larramendi", Muga 28, 66-81.

- ApV = Michelena 1955.

- Bahner, Werner. 1966. La lingüística española del siglo de oro. Aportaciones a la conciencia lingǘstica en la Espa ña de los siglos XVI y XVII. Jesús Munárriz Peraltaren gazt. itzulpena, egileak gainbegiratua eta eguneratua. Madril : Ciencia Nueva.

- Breva Claramonte, Manuel, 1985, "Prólogo", in Lázaro Carreter 1985, 7-34.

- Eco, Umberto, 1994 [1993], La búsqueda de la lengua perfecta, María Pons-en gazt. itzulpena. Bartzelona : Crítica.

- Genette, Gérard, 1976, Mimologiques. Voyage en Cratyle. París : Editions du Seuil.

- Gómez, Ricardo. 1992. "Larramendiren gramatika eta gramatikagintzaren historia", in Gómez \& Lakarra (arg.) 1992, 261-274.

- Gómez, Ricardo \& Joseba A Lakarra (arg.), 1992, Euskala ritzaren historiaz, I : XVI-XIX. mendeak, ASJU-ren gehigarriak, 15). Donostia : Gipuzkoako Aldundia/EHU.

- Hausmann et al. (arg.), 1989, Dictionaries. An International Encyclopedia of Lexicography. Berlin New York: Walter de Gruyter.

- Hüllen, Werner (arg.), 1990, Understanding the Historiography of Linguistics. Problems and Projects (Symposium at Essen, 23-25 November 1989). Münster : Nodus Publikationen.

- Jones, William Jervis, 1991, "Lingua teutonum victrix ? Landmarks in German lexicography", Histoire Épistémologie Langage 13 :2., 131-152.

- Koerner, E. F. Konrad, 1989, Practicing Linguistic Historiography. Amsterdam Philadelphia : Benjamins.

— Lakarra, Joseba A, 1985, "Larramendiren hiztegigintzaren inguruan", ASJU19 : 1, 9-50.

- Lakarra, Joseba A, 1993, XVIII. mendeko hiztegigintzaren etorkiez. Doktorego-tesi argitaragabea, EHU, Gasteiz.

- Lakarra, Joseba A, 1995, "Pouvreauren hiztegiez eta hiztegigintzaren historiaz", ASJU $29: 1,3-52$.

- Landucci, N[icolao], 1562, Dictionarium Linguae Cantabricae (1562). M. Agud eta K. Mitxelenaren arg., K. Mitxelenaren hitzaurrea. Donostia : Gipuzkoako Aldundia, 1958.

- Larramendi, Manuel de, 1728, De la a ntigüedad y universa lida d del Bascuenze en España: de sus perfecciones y ventajas sobre otras muchas Lenguas, Demonstración previa al Arte que se dará a luz desta Lengua. Salamanca : Eugenio García de Honorato. Berrarg. Bilbo : Ediciones Vascas, 1978.

- Larramendi, Manuel de, 1729, El Imposible Vencido. Arte de la Lengua Bascongada. Salamanca : A. J. Villagordo. Berrarg. faksim. Donostia : Hordago, 1979.

— Larramendi, Manuel de, 1745, Dicciona rio Trilingüe del Castella no, Bascuence y Latín (2 lib.). Donostia : Bartholomé Riesgo y Montero. Berrarg. faksim. Donostia : Txertoa, 1984. 
— Lázaro Carreter, Fernando, 1985 [1949], La s idea s lingüística en Espa ña durante el siglo XVIII. Revista de Filología Española-ren 48. gehigarria. Berrarg. Bartzelona : Crítica.

- Mayans, Gregorio, 1737, Orígenes de la Lengua Espa ñola. In Obras Completas II, Antonio Mestre Sanchís-en arg. Valencia : Publicaciones del Ayuntamiento de Oliva 12, 1984.

- Mitxelena, Koldo. 1955. Apellidos Vascos. (4. arg. Donostia : Txertoa, 1989).

- Mitxelena, Koldo. 1959, "La obra del P. Manuel de Larramendi (1690-1766)". Cuadernos de la Cátedra Feijoo 6. (Berrarg. in Mitxelena 1988 : 2, 900-912).

- Mitxelena, Koldo. 1983a, "Mendiburu eta Larramendi", Euskera 28 :1. Orain in SHLV, II, 912-915.

- Mitxelena, Koldo. 1983b, "Euskara eta euskararekiko ikerlanak (1700-1880)", Eusko Ika skuntza ren IX. Kongresoa, Bilbo. Orain in SHLV, II, 948-964.

— Mitxelena, Koldo. 1984, "Aurkezpena" in Sarasola 1984.

- Mitxelena, Koldo. 1988, Sobre Historia de la Lengua Vasca (2 lib.), Joseba A. Lakarraren arg., ASJU-ren gehigarriak 10. Donostia : "Julio de Urquijo" Euskal Filologi Mintegia.

— Mokoroa, Justo M., "Ibar", 1935, Genio y Lengua, Tolosa.

- Oyharçabal, Beñat. 1989. "Les travaux de grammaire basque avant Larramendi (1729)", ASJU 23 :1, 59-73.

— Pagola, Ines, 1984, "Neologismos en los Juegos Florales", ASJU 18 :1, 55-159.

- Sarasola, Ibon, 1986, "Larramendiren eraginaz eta", ASJU 20 :1, 203-215.

- Sarasola, Ibon, 1997, Euskal hiztegigintza XX. mendea arte. EHU-aren katedrarako txosten argitaragabea, Gasteiz.

- Seco, Manuel, 1987, Estudios de Lexicografía española. Madrid : Paraninfo.

- Seiffert, L., 1990, "The Vernacularist and Latinist Justus-Georgius Schottelius and the Traditions of German Linguistic Purism", in Hüllen (arg.) 1990, 241-261.

- Swiggers, P., 1990, "Reflections on (Models for) Linguistic Historiography", in Hüllen (arg.). 1990, 21-34.

- Tovar, Antonio, 1980, Mitología e ideología sobre la lengua va sca. Madrid: Alianza.

- Urgell, Blanca, 2000. Larramendiren Hiztegi Hirukoitza-ren osa ga iez. EHU-aren doktorego-tesi argitaragabea, Gasteiz.

- Urgell, Blanca, 2001, "El Dicciona rio de Autoridades de la Academia Española y el Dicciona rio Trilingüe del Ca stella no, Ba scuence y La tín (1745) del P. Larramendi", II Congreso Internacional de la Sociedad Española de Historiografía Lingüística, 907-918. Madril : Arco/Libros.

- Zgusta, Ladislav, 1989, "The Role of Dictionaries in the Genesis and Developement of the Standard", in Hausmann et al. (arg.), 70-79. 